\title{
Responsabilidade social e meio ambiente: a contabilidade como ferramenta essencial ao desenvolvimento sustentável
}

\section{José Felipe Pereira da Silva}

Faculdade de Ciências Humanas - ESUDA. Departamento de Ciências Contábeis. Rua Bispo Cardoso Ayres, S/№. Santo Amaro. Recife-PE (CEP 50050-100). E-mail: felipe.prof@outlook.com.

Resumo. Diante de diversas tragédias ambientais ocorridas nos últimos anos, espera-se que voluntariamente as empresas relatem periodicamente como a organização está respondendo ao arcabouço de normativos vigente, qual o programa de sustentabilidade empresarial em vigor, como a empresa identifica riscos ambientais no seu negócio, o que está fazendo para melhor prevenir esses riscos, ou pelo menos detectá-lo mais cedo para tomar medidas corretivas. 0 contador é peça fundamental na garantia das organizações realizarem o alinhamento da estratégia da obtenção dos resultados econômico e financeiros com as obrigações socioambientais. A pesquisa apresentou que $97 \%$ dos contadores compreendem que eles são os responsáveis por promover a transparência das ações da empresa e $83 \%$ dos contadores informaram que concorda com o grande benefício que a informação contábil pode gerar para os usuários da informação sobre os impactos ambientais gerados pelo negócio o qual a organização esta inserida.

Palavras-chave: Sustentabilidade empresarial; Contabilidade ambiental; Responsabilidade social.

\begin{abstract}
Social responsibility and the environment: accounting as an essential tool for sustainable development. In the face of several environmental tragedies that have occurred in recent years, it is expected that companies voluntarily report periodically how the organization is responding to the current normative framework, what business sustainability program is in place, how the company identifies environmental risks in its business, what it is doing to better prevent those risks, or at least detect it earlier to take corrective action. The accountant is a key element in ensuring that organizations align the strategy for obtaining economic and financial results with social and environmental obligations. The survey showed that $97 \%$ of the accountants understand that they are responsible for promoting the transparency of the company's actions and $83 \%$ of the Accountants reported that it agrees with the great benefit that the accounting information can generate for the users of the
\end{abstract}

Recebido:

21/01/2019

Aceito:

21/04/2019

Publicado:

$30 / 04 / 2019$

Acesso aberto

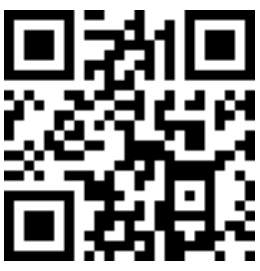

ORCID

(1) 0000-0002-8118-386X José Felipe Pereira da Silva 
information on the generated environmental impacts by the business in which the organization is inserted.

Keywords: Corporate sustainability; Environmental accounting; Social responsibility.

\section{Introdução}

A sociedade atualmente vive em um mundo com uma população crescente, buscando uma vida melhor, para que suas relações sejam construídas a partir de um planeta com recursos finitos, muitos dos quais estão agora rapidamente se esgotando. Neste sentido, as empresas estão sempre sob o prisma de atingir metas inalcançáveis, estimuladas pela intensa necessidade dos acionistas de avultar os seus lucros, despertando com isso uma inquietação dos gestores que compõe a organização na busca pela eficiência e eficácia na gestão dos recursos (Wickboldt et al., 2018).

Todavia, os colaboradores em todos os níveis da organização, incluindo os administradores, investidores, credores, auditores internos e externos, possuem a responsabilidade de lidar com a sustentabilidade empresarial. A Price Waterhouse Coopers (PWC), reconhecida entre as quatro maiores empresas de auditoria do mundo (big four), realizou um estudo em 2014 com 1.344 executivos (CEO's), com o objetivo de investigar a perspectiva desses profissionais quanto o impacto da sustentabilidade empresarial para o sucesso da organização. A pesquisa constatou que $75 \%$ dos CEO's concordam com a responsabilidade que as organizações precisam empregar ao se preocupar com os impactos ambientais do negócio o qual estão inseridos, bem como, as necessidades sociais da população protegendo os interesses das gerações futuras, a fim de atingirem melhores resultados tanto financeiros como na imagem da empresa.

Consolidando esse raciocínio, foi realizada uma pesquisa para avaliar a confiança dos consumidores de produtos e serviços pelo Instituto Edelman (Edelman, 2014), os resultados apontaram que $84 \%$ dos entrevistados afirmaram que as organizações devem alinhar a sua estratégia empresarial com programas sociais que possam de certa forma atender aos anseios da sociedade.

Estes fatos per si revelam que a sustentabilidade está na ordem do dia entre os temas mais relevantes da atualidade, portanto as grandes empresas devem considerar esta pauta como um pilar na estratégia do negócio e aspecto preponderante no processo de tomada de decisão.

Particularmente, espera-se que voluntariamente as empresas relatem periodicamente como a organização está respondendo ao arcabouço de normativos vigente, qual o programa de sustentabilidade empresarial em vigor, como a empresa identifica riscos ambientais no seu negócio, o que está fazendo para melhor prevenir esses riscos, ou pelo menos detectá-lo mais cedo para tomar medidas corretivas. Cada organização precisa avaliar o grau de ênfase que deve ser adotado na gestão de risco ambiental com base em seu tamanho e exposição ao risco. Hoje os órgãos reguladores estão mais sensibilizados para o risco ambiental do que antes. Por este motivo, as organizações passaram a empreender iniciativas em larga escala para melhorar o seu desempenho de negócios, gerenciando os custos, conscientizando às demandas das partes interessadas, $\mathrm{e}$ preparando-se para os requisitos regulamentares.

O contador é peça fundamental na garantia das organizações realizarem o alinhamento da estratégia da obtenção dos resultados econômico e financeiros com as obrigações socioambientais. A educação é um importante instrumento 
que deverá auxiliar nesse desafio, assumindo um papel relevante, sendo as instituições de ensino superior os representantes deste processo. De acordo com Silveira e Souza (2009), o processo de mudança na formação que constroem a atitude dos profissionais, devem considerar as relações ocorridas no meio socioeconômico e o dinamismo no desenvolvimento do país, sem perder de vista os valores éticos. Ainda segundo Silveira e Souza (2009), cada vez mais a relação entre produtividade e padrão de vida das pessoas deve ser considerada, cabendo às instituições de ensino superior assumir a responsabilidade de produzir bens e serviços adequados com qualidade, que possam contribuir no esperado desenvolvimento econômico e social, com objetivo de influenciar positivamente a vida das pessoas.

Diante das considerações apresentadas, emerge o seguinte questionamento: Podemos assegurar que o profissional contábil possui formação acadêmica de modo a atender os modelos de negócios que reconhecem a necessidade de integrar a sustentabilidade empresarial a suas estratégias operacionais fundamentais?

Sustentabilidade empresarial não é mais uma reflexão filantrópica ou apenas medidas ambientais, como coleta seletiva de resíduos sólidos ou instalação de lâmpadas de baixo consumo, mas sim um novo paradigma que deve ser incorporado ao planejamento estratégico da empresa, construindo um pensamento capaz de estimular os gestores da organização de forma responsável, possibilitando antever comportamentos que poderão mitigar os riscos ambientais inerentes ao negócio. De acordo com Gray (1998), a perspectiva mais frequentemente empregada para a sustentabilidade empresarial é que, do ponto de vista da responsabilidade e transparência, os contadores devem se basear no direito à informação da sociedade em uma democracia, na qual as empresas devem compartilhar a responsabilidade na utilização dos recursos finitos que dessa forma determinam futuro da população.

Segundo Lizote et al. (2014), a busca incessante pela transparência nas empresas faz com que o contador desempenhe uma função ímpar, sendo extremamente necessário em uma organização. Este profissional deve possuir características em seu perfil que compreenda a sustentabilidade empresarial não só pela preservação do meio ambiente, mas também pela inserção da sustentabilidade empresarial como estratégia para alcançar os objetivos econômicos e financeiros das empresas.

Assim sendo, este estudo torna-se relevante devido à preocupação quanto à formação do contador no atendimento as demandas geradas pela sustentabilidade empresarial, sendo considerada como um assunto que requer uma investigação minuciosa. No entanto, a pesquisa existente não provém um diagnóstico que municiem a literatura, a consolidar os conhecimentos já realizados sobre a formação do contador e o nível de atualização necessário, para ser proclamado como ferramenta imprescindível no processo de gestão da sustentabilidade empresarial.

Diante do exposto, o presente estudo tem por objetivo verificar a percepção dos profissionais de contabilidade quanto a sua formação no atendimento as demandas geradas pela sustentabilidade empresarial. Para tanto, desenvolveu-se uma pesquisa pelo método survey através de um questionário da plataforma do Formulário Google com o intuito de alcançar os seguintes objetivos específicos elencados a seguir:

- Descrever os conceitos de Contabilidade Ambiental;

- Avaliar o nível de conhecimento dos profissionais da área Contábil sobre os temas relacionados à sustentabilidade empresarial; e

- Contribuir com a literatura com os resultados auferidos na pesquisa. 
A expectativa desse estudo concerne em obter resultados empíricos relevantes de modo a contribuir o aperfeiçoamento da profissão contábil na abordagem da sustentabilidade empresarial, promovendo a compreensão teórica a respeito da Contabilidade Ambiental e que evidenciando a percepção do nível de conhecimento dos profissionais da área contábil sobre o assunto.

As questões ambientais, ecológicas e sociais, evidenciadas por estudos científicos relatam a relevância e a urgência de medidas mais coercitivas e tempestivas por parte das empresas, vêm fazendo com que os contadores e os gestores empresariais passem a considerá-las no Sistema de Gestão e no Sistema de Contabilidade dando ensejo ao reconhecimento da Contabilidade Ambiental. De acordo com Ferreira (2003) a degradação do meio ambiente demanda dos gestores a elaboração de informações financeiras compreensíveis que os auxiliem nesse grande desafio, contudo os contadores, de modo geral, não se encontram preparados atender a essa expectativa.

Estse fato acentuou-se na década de 1990, quando as consequências nocivas da degradação do meio ambiente proporcionaram um elevado índice de atenção mundial. De acordo com Ribeiro (2005), aproximadamente 175 chefes de estado realizaram uma conferencia na Organização das Nações Unidas (ONU) com a finalidade de discutir o tema: meio ambiente e desenvolvimento sustentável. Segundo Arifa (2012) a ECO-92 insere o homem no centro dos debates ambientais ao entender como foco as preocupações sobre o desenvolvimento sustentável, de modo a discutir uma vida produtiva e saudável, em harmonia com a natureza.

Posteriormente a realização da ECO-92 e em decorrência do agravamento dos problemas ambientais, de modo geral, Ferreira (2003) considera que fundamentado nos resultados da ECO-92, os contadores, órgãos de classe, entidades de pesquisa e os governos de vários países começaram a debater $\mathrm{o}$ tema, com o intuito de contribuir para o disciplinamento de novas condutas éticas, por meio de uma metodologia ou, ainda, de contribuir para o aprimoramento dos procedimentos e da metodologia contábil já existentes, com o objetivo de suportar as necessidades dos gestores por informações financeiras fidedignas sobre o meio ambiente e relativas à entidade.

Segundo Ferreira (2003), o Instituto Canadense de Contadores Certificados (Canadian Institute of Chartered Accountants - CICA), publicou em 1993 o relatório de pesquisa "Environmental costs and liabilities: Accounting and financial reporting issues". Este documento apresenta os procedimentos de avaliação de riscos ambientais, registro de responsabilidades por danos causados, capitalização e gastos relacionados ao meio ambiente a serem adotados pelo contador no processo de elaboração dos relatórios financeiros para os usuários da informação contábil (steakholder's), que devem ser enquadrados nesta corrente da Contabilidade Ambiental. De acordo com Cormier e Magnan (1997), enquanto a pesquisa sobre Contabilidade Social e geração de relatórios está enraizada no início década de 1970, os registros da Contabilidade Ambiental corporativa para prática profissional passaram a receber maior atenção após esse estudo publicado pelo CICA, em 1993.

Após uma década, em 2002, na Cidade de Johannesburgo, na África do Sul, ocorreu a Conferência Mundial sobre Desenvolvimento Sustentável (ou em inglês WSSD, World Summit on Sustainable Development), computando a participação de delegações de 168, países, para avaliar as ações concretizadas e os fracassos da implementação dos planos de sustentabilidade propostos na convenção anterior na Cidade do Rio de Janeiro. Ribeiro (2005) ressalta que, além de quantificar os resultados, a Conferência de Johannesburgo esta- 
beleceu novos desafios e ampliou $\mathrm{o}$ número de questões em virtude de novos acontecimentos que surgiram na última década. Segundo Lucon e Coelho (2002), os líderes de diversas nações, expandiram o escopo através da inclusão das novas metas denominadas Metas do Milênio, objetivando assegurar através de metas eficazes a sustentabilidade ambiental:

\begin{abstract}
[...] erradicar a fome e a pobreza extrema; alcançar uma mínima educação primária com iguais oportunidades para homens e mulheres; reduzir a mortalidade infantil com especial enfoque ao combate à AIDS e à malária; melhorar as condições de vida dos que moram em favelas e de outras populações mais necessitadas; ampliar o acesso à água potável; desenvolver uma parceria global para o desenvolvimento que incluísse sistemas internacionais de comércio e financiamento não discriminatórios e atendesse às necessidades especiais dos países em desenvolvimento, aliviando suas dívidas externas, provendo trabalho aos jovens e acesso a remédios e novas tecnologias.
\end{abstract}

A solução dos problemas de ordem ambiental exige o empenho de cada segmento da sociedade e a dedicação dos profissionais no desenvolvimento dos diversos ramos do conhecimento, e dessa forma contribuir de acordo com o seu potencial, ramo de atuação e habilidades práticas (Ribeiro, 2005). Considerando esse aspecto, Ferreira (2003) esclarece que a Contabilidade Ambiental através dos demonstrativos financeiros produzindo informações sobre os recursos econômicos da organização e seu impacto no patrimônio, considerando que a empresa deve mensurar os impactos ambientais que resultem em mudanças econômicas nesse recurso (meio ambiente).

Portando, podemos refletir no sentido que as organizações que possuem metas mais ávidas para atingirem a sustentabilidade, apresentarão a característica de estarem mais propensos a adotarem medidas que estejam de acordo com a conjuntura da sustentabilidade empresarial, sendo mais transparentes e fornecendo mais informações a sociedade sobre os impactos resultantes da sua atividade. Nesse contexto, os impactos provocados por esse modelo de negócio possuem estrutura adequada para as empresas investirem em novos controles e técnicas para atenderem as expectativas? Como segregar a estratégia finalística de maximização do lucro, com a preocupação do subproduto que será a mensuração dos danos, exaustão dos recursos de maneira sustentável? Esses questionamentos impactam diretamente a formação do perfil do profissional contábil, que deverá deter conhecimento técnico para atender a esses anseios inerentes aos negócios sujeitos a prática da Sustentabilidade Empresarial.

\section{Desastres ambientais}

Em um mundo dinâmico, complexo e competitivo, a atividade empresarial intensificada pela urbanização acelera a escassez de recursos aumentando as mudanças climáticas. Esses relatos descrevem uma tendência que assola a sociedade e o mundo dos negócios impactando na sustentabilidade empresarial e no sucesso das empresas. No Brasil, nos últimos 35 anos vários desastres ambientais aconteceram provocando múltiplos problemas em todos os biomas, comprometendo os recursos naturais. A seguir apresentamos algumas dessas catástrofes e os respectivos impactos ambientais, econômico e financeiro resultantes.

Pode-se verificar na Tabela 1 a importância da Contabilidade Ambiental no auxílio à sociedade de um modo geral, em virtude do impacto ambiental ocasionado por diversos tipos de negócios, bem como mensurar os valores pagos aos órgãos reguladores pelos 
problemas ambientais gerados. No entanto, como as empresas provocam diversos impactos ambientais, econômico e financeiro, a sociedade passou a cobrar medidas preventivas sob a responsabilidade por meio da sustentabilidade empresarial, sendo utilizada a
Contabilidade Ambiental como instrumento desse grande desafio para evidenciar tais registros de modo a promover a transparência dos processos e aumentar o nível de responsabilidade por negócios sustentáveis.

Tabela 1. Desastres ambientais ocorridos no Brasil entre 1984 e 2019.

\begin{tabular}{|c|c|c|c|c|c|}
\hline Ano & Empresa & Fato & Descrição & Impacto ambiental & Impacto financeiro \\
\hline 1984 & $\begin{array}{l}\text { Petróleo } \\
\text { Brasil S.A. } \\
\text { (Ferreira, } \\
\text { 2007) }\end{array}$ & Incêndio & $\begin{array}{l}\text { O vazamento em dutos } \\
\text { subterrâneos da } \\
\text { Petrobras espalhou } \\
700 \text { mil litros de } \\
\text { gasolina nos arredores } \\
\text { da Vila Socó, } \\
\text { Cubatão-SP. }\end{array}$ & $\begin{array}{c}\text { Destruição de } \\
\text { moradias e mortes de } \\
\text { dezenas de pessoas. }\end{array}$ & $\begin{array}{l}\text { Pagamento de multa à } \\
\text { Companhia Ambiental } \\
\text { do Estado de São } \\
\text { Paulo (CETESB) }\end{array}$ \\
\hline 1987 & $\begin{array}{c}\text { Instituto } \\
\text { Goiano de } \\
\text { Radioterapia } \\
\text { (IGR) (IAEA, } \\
\text { 1988; Anjos } \\
\text { et al., 2001; } \\
\text { Vieira, 2009) }\end{array}$ & $\begin{array}{l}\text { Acidente } \\
\text { com } \\
\text { material } \\
\text { radioativo }\end{array}$ & 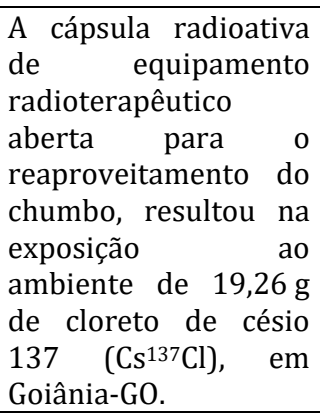 & $\begin{array}{l}\text { Monitoramento de } \\
112.800 \text { pessoas, } \\
\text { sendo identificadas } \\
1.600 \text { pessoas } \\
\text { afetadas e quatro } \\
\text { mortes. }\end{array}$ & $\begin{array}{l}\text { Os médicos donos do } \\
\text { Instituto e o físico } \\
\text { responsável foram } \\
\text { condenados por } \\
\text { homicídio culposo a } \\
\text { três anos de prisão. } \\
\text { Foi cumprido um ano } \\
\text { de pena e o restante } \\
\text { substituído por } \\
\text { serviços prestados à } \\
\text { comunidade. }\end{array}$ \\
\hline 2000 & $\begin{array}{l}\text { Petróleo } \\
\text { Brasil S.A. } \\
\text { (Monteiro, } \\
\text { 2003) }\end{array}$ & $\begin{array}{c}\text { Vazamento } \\
\text { de óleo }\end{array}$ & $\begin{array}{l}\text { O vazamento de } 1,3 \\
\text { milhão de litros de } \\
\text { óleo in natura de um } \\
\text { navio petroleiro na } \\
\text { Baía de Guanabara, no } \\
\text { Rio de Janeiro-RJ. }\end{array}$ & $\begin{array}{c}\text { Desaparecimento de } \\
\text { inúmeras espécies de } \\
\text { fauna e flora, prejuízos } \\
\text { de ordem social e } \\
\text { econômica a } \\
\text { população, que tirava } \\
\text { o sustento as } \\
\text { atividades de pesca na } \\
\text { baia. } \\
\end{array}$ & $\begin{array}{l}\text { Multa de } \mathrm{R} \$ 51,5 \\
\text { milhões }\end{array}$ \\
\hline 2000 & $\begin{array}{l}\text { Petróleo } \\
\text { Brasil S.A. } \\
\text { (Brehm e } \\
\text { Richter, } \\
\text { 2013) }\end{array}$ & $\begin{array}{c}\text { Vazamento } \\
\text { de óleo }\end{array}$ & $\begin{array}{c}\text { Vazamento de } 4 \\
\text { milhões de litros óleo } \\
\text { da refinaria } \\
\text { Presidente Getúlio } \\
\text { Vargas, em } \\
\text { Araucária-PR. }\end{array}$ & $\begin{array}{c}\text { Desaparecimento de } \\
\text { inúmeras espécies de } \\
\text { fauna e flora, prejuízos } \\
\text { graves de ordem } \\
\text { social e econômica a } \\
\text { população, que tirava } \\
\text { o sustento as } \\
\text { atividades de pesca na } \\
\text { baia. } \\
\end{array}$ & $\begin{array}{l}\text { Próximo de R } \$ 1,4 \\
\text { bilhões multas }\end{array}$ \\
\hline 2003 & $\begin{array}{c}\text { Indústria } \\
\text { Cataguases } \\
\text { de Papel Ltda } \\
\text { (Gonçalves, } \\
\text { 2007) }\end{array}$ & $\begin{array}{l}\text { Rompimento } \\
\text { de barragem }\end{array}$ & $\begin{array}{l}\text { O rompimento de } \\
\text { barragem de celuluse } \\
\text { na região de } \\
\text { Cataguases-MG, com } \\
\text { vazamento de } 1,4 \\
\text { bilhões } \mathrm{m}^{3} \text { de rejeitos } \\
\text { compostos por } \\
\text { resíduos orgânicos e } \\
\text { soda cáustica. }\end{array}$ & $\begin{array}{c}\text { Poluição dos Rios } \\
\text { Pomba e Paraíba do } \\
\text { Sul, contaminação da } \\
\text { biota aquática, do solo } \\
\text { e de vegetais } \\
\text { superiores e } 600 \text { mil } \\
\text { pessoas sem água. }\end{array}$ & $\begin{array}{c}\text { Cerca de R } \$ 50 \\
\text { milhões em multas }\end{array}$ \\
\hline
\end{tabular}


Tabela 1. Continuação.

\begin{tabular}{|c|c|c|c|c|c|}
\hline Ano & Empresa & Fato & Descrição & Impacto ambiental & Impacto financeiro \\
\hline 2007 & $\begin{array}{l}\text { Rio Pomba } \\
\text { Cataguases } \\
\text { Ltda } \\
\text { (Teixeira, } \\
\text { 2016) }\end{array}$ & $\begin{array}{l}\text { Rompimento } \\
\text { de barragem }\end{array}$ & $\begin{array}{l}\text { Rompimento de } \\
\text { barragem de } \\
\text { mineração na região } \\
\text { de Miraí-MG, com } \\
\text { vazamento de } 2,28 \\
\text { bilhões de } \mathrm{m}^{3} \text { de água } \\
\text { e argila. }\end{array}$ & $\begin{array}{c}\text { Mais de } 6 \text { mil pessoas } \\
\text { desalojadas e } 1.200 \\
\text { casas destruídas, falta } \\
\text { de água potável } \\
\text { devido aos } \\
\text { sedimentos de lama } \\
\text { intensificaram o } \\
\text { assoreamento dos } \\
\text { rios. }\end{array}$ & $\begin{array}{c}\text { Prejuízo de cerca de } \\
75 \text { milhões para o } \\
\text { Município de Miraí } \\
\text { (MG). }\end{array}$ \\
\hline 2011 & $\begin{array}{l}\text { Crevron } \\
\text { Corp. (Silva e } \\
\text { Soares, } \\
2013 \text { ) }\end{array}$ & $\begin{array}{l}\text { Vazamento } \\
\text { de óleo }\end{array}$ & $\begin{array}{c}\text { Vazamento de uma } \\
\text { grande quantidade de } \\
\text { óleo da Chevron na } \\
\text { Bacia de Campos, no } \\
\text { Rio de Janeiro-RJ. } \\
\text { Estima-se que a } \\
\text { mancha provocada } \\
\text { pelo vazamento no } \\
\text { mar tenha chegado a } \\
162 \mathrm{~km}^{2}, \mathrm{o} \\
\text { equivalente a metade } \\
\text { da Baía de Guanabara. }\end{array}$ & $\begin{array}{c}\text { Poluição do } \\
\text { ecossistema marinho } \\
\text { podendo levar a } \\
\text { extinção de espécies, } \\
\text { impactos as atividades } \\
\text { econômicas da região. }\end{array}$ & $\begin{array}{l}\text { Por volta de R\$ } 35 \\
\text { milhões em multas }\end{array}$ \\
\hline 2015 & $\begin{array}{l}\text { Ultracargo } \\
\text { S.A. (Arôxa et } \\
\text { al., 2016) }\end{array}$ & Incêndio & $\begin{array}{l}\text { Incêndio no Terminal } \\
\text { Alemoa, devido ao } \\
\text { lançamento de } \\
\text { efluentes líquidos no } \\
\text { Estuário de Santos-SP, } \\
\text { em manguezais e na } \\
\text { lagoa ao lado do } \\
\text { terminal, além de } \\
\text { emitir efluentes } \\
\text { gasosos na atmosfera. }\end{array}$ & $\begin{array}{l}\text { Poluição por efluentes } \\
\text { líquidos no estuário, } \\
\text { em manguezais e a } \\
\text { mortandade de peixes. }\end{array}$ & $\begin{array}{l}\text { Próximo de } \mathrm{R} \$ 22,5 \\
\text { milhões em multas }\end{array}$ \\
\hline 2015 & $\begin{array}{l}\text { Samarco } \\
\text { Mineração } \\
\text { S.A. (Lacaz et } \\
\text { al., 2017) }\end{array}$ & $\begin{array}{l}\text { Rompimento } \\
\text { de barragem }\end{array}$ & $\begin{array}{c}\text { Rompimento da } \\
\text { barragem pela } \\
\text { Samarco em Mariana- } \\
\text { MG, provocou a } \\
\text { liberação de } 62 \\
\text { milhões de metros } \\
\text { cúbicos de rejeitos no } \\
\text { Rio Doce. }\end{array}$ & $\begin{array}{l}\text { Poluição da bacia do } \\
\text { Rio Doce e do } \\
\text { ecossistema marinho } \\
\text { podendo levar a } \\
\text { extinção de espécies. } \\
\text { Destruição de } \\
\text { Moradias e } 19 \text { mortos. }\end{array}$ & $\begin{array}{l}\text { Cerca de } \mathrm{R} \$ 610 \\
\text { milhões em multas e } \\
\text { autos de infração }\end{array}$ \\
\hline 2019 & Vale S.A. ${ }^{10}$ & $\begin{array}{l}\text { Rompimento } \\
\text { de barragem }\end{array}$ & $\begin{array}{c}\text { Rompimento da } \\
\text { barragem de rejeito da } \\
\text { Vale, em Brumadinho- } \\
\text { MG, provocou a } \\
\text { liberação de } 12 \\
\text { milhões }{ }^{3} \text { de rejeitos } \\
\text { no Córrego do Feijão, } \\
\text { afluente do Rio } \\
\text { Parauapebas. }\end{array}$ & $\begin{array}{l}115 \text { Mortes, poluição } \\
\text { da Bacia do Rio São } \\
\text { Francisco, podendo } \\
\text { levar à extinção de } \\
\text { espécies, impactos nas } \\
\text { atividades econômicas } \\
\text { da região. }\end{array}$ & $\begin{array}{c}\text { Cerca de R\$ } 349 \\
\text { milhões em multas }\end{array}$ \\
\hline
\end{tabular}

7Disponível em: <http://g1.globo.com/rio-de-janeiro/noticia/2012/07/chevron-poderia-ter-evitadovazamento-diz-relatorio-da-anp.html>. Acesso em 02 fev. 2019.

8Disponível em: <http://g1.globo.com/sp/santos-regiao/noticia/2015/04/cetesb-multa-ultracargo-em-maisde-r-22-mi-apos-incendio-em-santos.html>. Acesso em: 02 fev. 2019.

${ }^{10}$ Disponível em: <https://www.bbc.com/portuguese/brasil-47002609>. Acesso em: 02 fev. 2019.

Segundo Freitas (2012) os países em desenvolvimento como o Brasil tem gerado oportunidades de melhoria de vida para milhões de pessoas devido ao 
crescimento econômico. Contudo, este cenário de geração de emprego e renda, não tem sido acompanhado por uma estrutura de prevenção a possíveis desastres ambientais potencializado por atividades de exploração a recursos naturais. Diante deste prisma, o estudo desenvolvido por Cassali (2017) ressalta que os países desenvolvidos convivem com uma dicotomia cotidiana entre a produção em larga escala mola propulsora da economia, em detrimento dos impactos nocivos ao meio ambiente.

Para muitos, o ponto de partida para compreender e agir sobre sustentabilidade tem-se centrado em torno de "fazer o bem" com os lucros obtidos e responsabilidade social corporativa. É tendiam a operar em um silo, separar-se da tomada de decisões estratégicas do negócio. Mas agora, o foco para o negócio está se voltando para uma compreensão mais holística de como ele faz lucro em primeiro lugar, as implicações, consequências e benefícios não só para ele, mas para a sociedade. Por isso, não é mais uma reflexão tardia filantrópica ou sobre a instalação de lâmpadas de baixo consumo, mas uma abordagem para incorporar 0 pensamento de vanguarda e responsável na prática de negócios e na forma como a empresa produz e fornece os seus produtos e serviços.

\section{Aspectos conceituais da Contabilidade Ambiental}

Com o aumento da interação das relações humanas, a Contabilidade enquanto Ciência Social modifica-se de modo a atender as novas expectativas da sociedade. 0 aprimoramento da Contabilidade através dos registros ambientais é respaldado pela necessidade emergente de fornecer informações úteis e relevantes pra a sustentabilidade empresarial. Ferreira (2003) destaca que é importante frisar que a Contabilidade Ambiental não é uma reformulação da Contabilidade, mas trata-se de um conjunto de proce dimentos de modo a produzir informações que relatem adequadamente, em termos econômicos (quantitativos), as estratégias definidas pela organização que resultem em alteração no patrimônio. Esse modelo corrobora a Contabilidade ao patamar de condicionante primordial ao processo de tomada de decisão nas organizações.

Segundo Ribeiro (2005), a Contabilidade Ambiental não deve ser tratada como uma nova ciência, mas sim, segmento da Contabilidade que identifica, mensura e esclarece os eventos e transações econômicas e financeiras que estejam inseridas no hall de proteção, preservação e recuperação ambiental, ocorridos em um determinado período, visando a evidenciação do impacto gerado na situação patrimonial da empresa. No entanto, a Contabilidade, como ferramenta de mensuração do patrimônio das empresas, reconhece a sua missão ao inserir os novos procedimentos com o objetivo da produção de informações fidedignas sobre os impactos ambientais. De acordo com Paiva (2003) a Contabilidade Ambiental deve ser considerada como o instrumento que pode auxiliar os usuários da informação na identificação de dados e registros de eventos ambientais, processando e gerando de informações que subsidiem o usuário servindo com parâmetro em suas tomadas de decisões.

Em síntese, conforme descrito por Ribeiro (2005) a contribuição gerada pela Contabilidade Ambiental é demonstrada através da evidenciação das informações dos recursos naturais de forma segregada, com o objetivo de inserir o usuário da informação contábil a compreender os desafios propostos a organização ao mitigar os riscos do negócio relacionados ao meio ambiente. Isto requer que os eventos e transações econômicos financeiros, relacionados com essa questão, sejam identificados, mensurados e contabilizados. 


\section{Gastos ambientais}

De acordo com Martins (2003), os gastos são definidos como a aquisição de matérias-primas, Gastos com mão-de-obra, honorários da diretoria, compra de imobilizado etc. Para Vellani e Ribeiro (2009), os gastos ambientais são conceituados como o total de recursos consumidos pelas atividades ambientais.

De maneira holística, a

Contabilidade registra os gastos ambientais, ao reconhecer os dispêndios relacionados as saídas de caixa com finalidade as ações ambientais, ou que de alguma forma, reserve alguma congruência com o tema meio ambiente, resultando em modificação no patrimônio da organização no momento de sua ocorrência ou no reconhecimento de maneira prudente para os gastos futuros.

\section{Ativos ambientais}

O Comitê de Pronunciamentos Contábeis (CPC) emitiu o Pronunciamento CPC 00 (R1) - Estrutura Conceitual das Demonstrações Contábeis (CPC, 2011), que define ativo como "um recurso controlado pela entidade como resultado de eventos passados e do qual se espera que fluam futuros benefícios econômicos para a entidade". Diante do exposto, Santos (2014) conceitua ativo ambiental como os bens e direitos destinados ou provenientes da atividade de gerenciamento ambiental.

Kraemer (2001) acrescenta que o ativo ambiental é representado pelos estoques dos insumos, peças, acessórios, etc. Utilizados no processo de eliminação ou redução dos níveis de poluição; os investimentos em máquinas, equipamentos, instalações, adquiridos ou produzidos com a intenção de amenizar os impactos causados ao meio ambiente.

Podemos sintetizar o conceito de ativos ambientais como sendo os recursos controlados pelas empresas, que tenham capacidade de geração de benefício econômico destinados ou provenientes de atividades ambientais.

\section{Passivos ambientais}

O CPC também definiu o conceito de passivo através do CPC 00 (R1), como "uma obrigação presente da entidade, derivada de eventos passados, cuja liquidação se espera que resulte na saída de recursos da entidade capazes de gerar benefícios econômicos".

Conforme previsto nas Normas e Procedimento de Auditoria NPA 11, emitida pelo Instituto Brasileiro de Contadores (IBRACON), o passivo ambiental é conceituado como toda a investida em desfavor do meio ambiente devendo ser mensurado o valor necessários para recuperar, podendo também ser na forma de multas ou indenizações aplicadas pelos órgãos reguladores (IBRACON, 1996).

De acordo com Andrade et al. (2015) passivo ambiental é a expectativa do sacrifício de benefícios futuros determinados pelo arcabouço normativo vigente, sendo o valor aplicado por meio de taxas, contribuições, multas e penalidades por infrações legais e ressarcimento a terceiros. Segundo Paiva (2003), as obrigações são decorrentes da relação entre a empresa e meio ambiente podendo surgir por meio do não cumprimento da legislação ambiental vigente ou ainda de problemas de manutenção ou falhas humanas relacionadas com etapas de produção, potenciais causadores de acidentes. Paiva (2003) ainda ressalta que o passivo ambiental também deve ser reconhecido em função do registro de multas e penalidades, sendo o seu fato gerador a degradação do meio ambiente.

\section{Metodologia}

A pesquisa se propõe a verificar a percepção dos profissionais de Contabilidade quanto a sua formação no atendimento as demandas geradas pela sustentabilidade empresarial.

O público-alvo desta pesquisa são contadores com a formação de nível superior concluída, sob a premissa de que essa parcela da sociedade esteja 
diretamente envolvida e interessada no desenvolvimento do perfil do profissional contábil em detrimento das demandas geradas pelas empresas em virtude da sustentabilidade empresarial. A pesquisa utilizou-se de um desenho de pesquisa do tipo exploratório-descritiva, com o objetivo de responder a questão de pesquisa, investigando a literatura disponível, com intuito de conceituar, esclarecer e desenvolver conceitos relacionados com o tema proposto.

Optou-se pelo método survey através de um questionário da plataforma do Formulário Google por este instrumento por se tratar de uma forma eficiente, rápida e organizada de coletar estes dados, bem como a facilidade de acesso dos contadores a esta ferramenta disponibilizada por meio da internet. 0 formulário é composto de 14 questões elaboradas para respostas estruturadas por meio da Escala Likert (1932), que compreende opções de respostas positiva ou negativa, sendo aplicado no mês de abril de 2016, com uma amostra não probabilística e intencional de 47 de contadores atuantes no Município de Recife-PE escolhidos por critério de conveniência.

\section{Resultados e discussão}

A partir dos questionários respondidos pelos participantes, as informações foram organizadas e analisadas por meio de um extrato apresentado pela plataforma do Google. Posteriormente, esses dados foram interpretados dentro de um contexto amplo, com o intuito de atingir o objetivo do estudo.

A Figura 1 mostra a faixa etária da amostra, onde se percebe que a maioria $(61,7 \%)$ dos profissionais possui de 26 a 35 anos, que surpreendeu por se achar que se trataria de profissionais com uma faixa etária maior, devido à responsabilidade assumida pelo contador nas organizações.

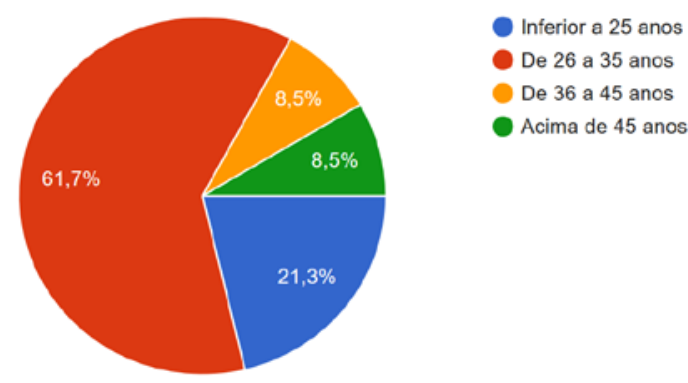

Figura 1. Faixa etária dos entrevistados.

Quando perguntados qual o grau de experiência dos profissionais (Figura 2 ), constata-se que $89,4 \%$ dos profissionais tem experiência inferior a cinco anos de trabalho realizados na área contábil. Outro dado interessante, é que apenas $6,4 \%$ dos respondentes, apresentaram uma experiência maior que 11 anos. Este fato aponta uma inexperiência dos profissionais entrevistados que pode suscitar uma maior dificuldade no conhecimento técnico na área de Contabilidade Ambiental.

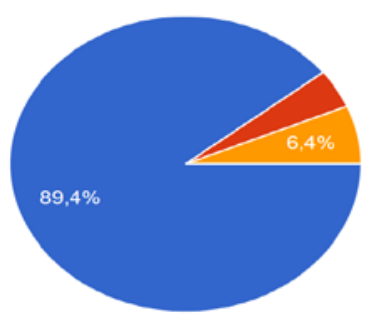

- inferior a 5 anos de 6 a 10 anos de 11 a 15 anos acima de 15 anos

Figura 2. Experiência profissional dos entrevistados.

Com relação à pergunta se o contador durante sua formação acadêmica havia cursado alguma disciplina ou participou de curso sobre Contabilidade Ambiental, 72,3\% afirmaram que sim e 27,7\% disseram não. 
Perguntado sobre o seu interesse em participar em adquirir e aprofundar conhecimentos sobre a área de Contabilidade Ambiental, 85\% dos contadores entrevistados possui interesse em adquirir e aprofundar conhecimentos sobre a área de Contabilidade Ambiental, enquanto $14,9 \%$ responderam que não. Isto implica dizer que, por se tratar de uma amostra com faixa etária de jovens e com pouca experiência, o aperfeiçoamento na área de Contabilidade Ambiental pode aumentar as chances de novas oportunidades de trabalho.

Quando perguntado se o profissional acredita que o contador possui uma carreira promissora na área de Sustentabilidade Empresarial, foi surpresa constatar que $23,4 \%$ dos entrevistados não acredita que 0 contador possui um papel relevante na sustentabilidade empresarial, enquanto $76,6 \%$ responderam que não. Este resultado apresenta uma grande preocupação, visto que é nítida a relevância da profissão contábil no processo de transparência e quanto às informações contábeis podem auxiliar no processo de tomada de decisão referente aos impactos ambientais, mas não foi percebido pelos contadores entrevistados.

Ao ser questionado sobre o papel do contador na sustentabilidade empresarial, constatou-se que mais de $78,7 \%$ dos contadores entrevistados responderam que não existe alinhamento entre a estratégia da organização e a sustentabilidade empresarial, enquanto $21,3 \%$ disseram que sim. Isso pode ter uma relação direta com o baixo interesse dos contadores em investirem na carreira na Contabilidade Ambiental, visto que a organização não define o tema como estratégico para entidade.

Ao se tratar sobre o papel do contador nos desafios do atendimento às demandas geradas pela sustentabilidade empresarial, evidenciamos que mais de $97,8 \%$ define que o contador deve prover a transparência das ações da empresa em busca do desenvolvimento sustentável. Este patamar revela que os profissionais compreendem que a contabilidade ambiental auxilia os usuários da informação contábil a prestarem contas sobre as atividades relacionadas ao meio ambiente que impactam no patrimônio da organização.

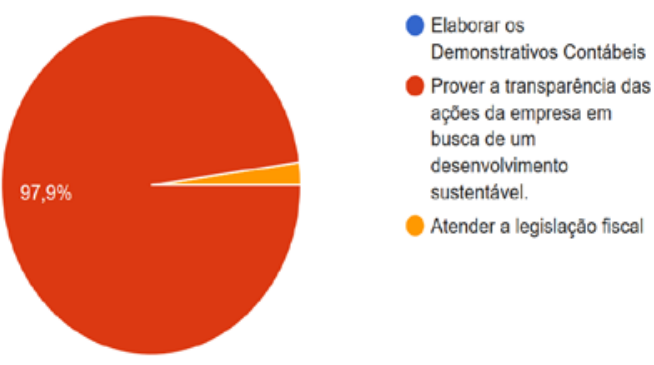

Figura 3. Papel do contador na Sustentabilidade Empresarial.

Ao ser questionado se a elaboração de relatórios e demonstrativos referentes à sustentabilidade empresarial pode gerar benefícios para os usuários, $83 \%$ dos contadores entrevistados concorda que o benefício gerado pelos dados fornecidos superam os custos para elaborá-los, concordando com o grande benefício que a informação contábil pode gerar para os usuários da sobre os impactos ambientais gerados pelo negócio o qual a organização esta inserida, enquanto $17 \%$ responderam que não geram benefícios.

\section{Conclusão}

O usuário da informação contábil não possui informações suficientes para diagnosticar em qual das posições a empresa se enquadra, tampouco para determinar sua dimensão temporal. Diante dos desastres ambientais relatados no estudo, ficou evidenciado a necessidade de transparência dos gastos e provisões ambientais, nos moldes em que é efetuada, podendo promover o 
aumento da capacidade informativa dos relatórios contábeis, proporcionando aos usuários da informação contábeis, sociais e ambientais melhores condições para fazer projeções sobre o desempenho futuro das organizações. A pesquisa apresentou que $97 \%$ dos Contadores compreendem que eles são os responsáveis por promover a transparência das ações da empresa em busca do desenvolvimento sustentável através dos Demonstrativos Contábeis.

$\begin{array}{cccc}\text { Cabe à } & \text { Contabilidade a } \\ \text { formulação de } & \text { parâmetros de }\end{array}$
mensuração e registro que permitam o acompanhamento da convivência da empresa com o meio ambiente e a evolução econômica e patrimonial de tal relação, no decorrer do tempo. 0 estudo apresentou que $83 \%$ dos contadores informaram que concorda com o grande benefício que a informação contábil pode gerar para os usuários da informação sobre os impactos ambientais gerados pelo negócio o qual a organização esta inserida. Esta afirmação justifica-se pela função da Contabilidade no tempo e na história, mesmo porque é a contabilidade quem efetua os registros dos eventos e transações econômicas das empresas através da abordagem sistêmica, gerando os relatórios onde tais informações estarão disponibilizadas.

Sendo assim, podemos concluir que os objetivos da pesquisa foram alcançados e que ficou evidente a contribuição da pesquisa quanto à necessidade de aperfeiçoamento para os contadores para atenderem aos anseios da sociedade quando há transparências das atividades que promovam impacto ao meio ambiente.

\section{Conflito de interesses} de interesses.

O autor declara não haver conflito

\section{Referências}

Andrade, V. A.; Santos, R. S.; Cezar, J. F. Contabilidade ambiental: nível de conhecimento dos profissionais da Área Contábil de Itaperuna. Revista Transformar, v. 7, p. 325-341, 2015. Disponível em: <http://www.fsj.edu.br/transformar/index.p $\mathrm{hp} /$ transformar/article/view/48/45>.

Acesso em: 22 abr. 2018.

Anjos, R. M.; Facure, A.; Lima, E. L. N.; Gomes, P. R. S.; Santos, M. S.; Brage, J. A.P. Radioactivity teaching: Environmental consequences of the radiological accident in Goiânia (Brazil). American Journal of Physics, v. 69, n. 3, p. 377-381, 2001. https://doi.org/10.1119/1.1315603

Arifa, B. I. A. O novo Código Florestal e a ECO-92. Revista de Direito Internacional, v. 9, n. 3, p. 97-106, 2012.

Arôxa, B. H.; Silva, D. O.; Pacini, A. A.; Bastos, E. J. B. Análise das emissões de material particulado (MP10) durante incêndio em tanques de combustível em Santos (SP). Anais do XX Encontro Latino Americano de Iniciação Científica, XVI Encontro Latino Americano de Pós-Graduação e VI Encontro de Iniciação à Docência, da Universidade do Vale do Paraíba, 2016.

Brehm, F. A.; Richter, L. Avaliação da contaminação dos sedimentos do Rio Iguaçu e Barigui por derivados do petróleo. Curitiba: Universidade Federal Tecnológica do Paraná, 2013. (Trabalho de conclusão de curso).

Cassali, N. K. Desastres ambientais: regulação e métodos de compensação. Revista de Direito da Empresa e dos Negócios, v. 1, n. 2, p.107-126, 2017. Disponível em: <http://www.revistas.unisinos.br/index.php /rden/article/view/15750>. Acesso em: 06 fev. 2019.

CNDH - Conselho Nacional dos Direitos Humanos. Relatório da missão emergencial a Brumadinho/MG após rompimento da Barragem da Vale S/A. Brasília: Conselho Nacional dos Direitos Humanos, 2019.

Cormier, D.; Magnan, M. Investors' assessment of implicit environmental liabilities: An empirical investigation. Journal of Accounting and Public Policy, v. 16, n. 2, p. 215-241, 1997. https://doi.org/10.1016/S0278-4254(97) 00002-1

CPC - Comitê de Pronunciamentos Contábeis. PC 00 (R1) - Estrutura Conceitual para 
Elaboração e Divulgação de Relatório Contábil-Financeiro. Brasília: CPC, 2011.

Edelman. Edelman Trust Barometer. Global Results. 2014. Disponível em: <https://www.edelman.com/research/2014edelman-trust-barometer>. Acesso em: 22 abr. 2018.

Ferreira, A. C. S. Contabilidade Ambiental: uma informação para o desenvolvimento sustentável. São Paulo: Atlas, 2003.

Ferreira, L. G. A gestão ambiental do pólo industrial de Cubatão a partir do programa de controle da poluição iniciado em 1983: atores, instrumentos e indicadores. São Paulo: Universidade de São Paulo, 2007. (Dissertação de mestrado).

Freitas, C. M.; Carvalho, M. L.; Ximenes, Arraes, E. F.; Gomes, J. O. Vulnerabilidade socioambiental, redução de riscos de desastres e construção da resiliência: lições do terremoto no Haiti e das chuvas fortes na Região Serrana, Brasil. Ciência \& Saúde Coletiva, v. 17, n. 6, p. 1577-1586, 2012. https://doi.org/10.1590/S1413-81232012 000600021

Gonçalves, J. B.; Almeida, J. R.; Lins, G. A. Uma análise crítica do acidente em Cataguases (MG) (2003). Revista Ciências do Ambiente On-Line, v. 3, n. 2, p. 89-91, 2007.

Gray, R. H. Imagination, a bowl of petunias and social accounting. Critical Perspectives on Accounting, v. 9, n. 2, p. 205-216, 1998.

IAEA - International Atomic Energy Agency. The radiological accident in Goiania. Viena: IAEA, 1988. Disponível em: <https://www-pub.iaea.org/MTCD/

publications/PDF/Pub815_web.pdf>. Acesso em: 06 fev. 2019.

IBRACON - Instituto Brasileiro de Contadores. Procedimento de Auditoria NPA 11 - Balanço e Ecologia. São Paulo: IBRACON, 1996.

Kraemer, M. E. P. Contabilidade ambiental o passaporte para a competitividade. Revista Catarinense da Ciência Contábil, v. 1, n. 1, p. 25-40, 2001. https://doi.org/10.16930/ 2237-7662/rccc.v1n1p25-40

Lacaz, F. A. C.; Porto, M. F. S.; Pinheiro, T. M. M. Tragédias brasileiras contemporâneas: 0 caso do rompimento da barragem de rejeitos de Fundão/Samarco. Revista Brasileira de Saúde Ocupacional, v. 42, e9, 2017. https://doi.org/10.1590/2317-6369000016

Likert, R. A technique for the measurement of attitudes. Archives of Psychology, v. 22, n. 140, p.1-55, 1932. Disponível em: <https://legacy.voteview.com/pdf/Likert_19 32.pdf>. Acesso em: 06 fev. 2019.

Lizote, S. A.; Verdinelli, M. A.; Couto, M.; Coelho, M.; Costa, N.; Bondan Junior, W. A. Responsabilidade social no meio acadêmico: um estudo com alunos de Ciências Contábeis. Anais do XIV Colóquio Internacional de Gestão Universitária - CIGU, Florianópolis, 2014.

Lucon, O.; Coelho, S. Depois da Rio+10: As lições aprendidas em Johannesburgo. Revista do Departamento de Geografia, v. 15, p.11-18, 2002. https://doi.org/ 10.7154/RDG.2002.0015.0001

Martins, E. Contabilidade de custos. 9. ed. São Paulo: Atlas, 2003.

Monteiro, A. G. Metodologia de avaliação de custos ambientais provocados por vazamento de óleo: o estudo de caso do Complexo REDUC-DTSE. Rio de Janeiro: Universidade Federal do Rio de Janeiro, 2003. (Dissertação de mestrado).

Paiva, P. R. Contabilidade Ambiental: evidenciação dos gastos ambientais com transparência e focada na prevenção. São Paulo: Atlas, 2003.

Ribeiro, W.C. A Ordem Ambiental Internacional. 2 ed. São Paulo: Contexto, 2005.

Santos, H. L. Contabilidade Ambiental: percepção dos profissionais contábeis da Cidade de Alta Floresta. Revista Eletrônica da Faculdade de Alta Floresta, v. 3, n. 4, p. 146-164, 2014.

Silva, M. A.; Soares, W. L. Efeito ambiental da poluição hídrica a partir do derramamento indiscriminado de petróleo. Brasília: Faculdades Integradas Promove de Brasília, 2013. (Trabalho de conclusão de curso).

Silveira, S. A. D.; Souza, A. H. C. Contabilidade Ambiental: a redefinição de um perfil profissional. Revista Eletrônica de Ciências Sociais, História e Relações Internacionais, v. 2, n. 1, p. 1-24, 2009. 
Thomé, R.; Passini, M. L. Barragens de rejeitos de mineração: características do método de alteamento para montante que fundamentaram a suspensão de sua utilização em minas gerais. Ciências Sociais Aplicadas em Revista, v. 18, n. 34, p. 49-65, 2018.

Teixeira, A.C.E. A. A observância dos princípios da informação e da participação no contexto de acidentes ambientais: estudo de caso. Belo Horizonte: Escola Superior Dom Helder Câmara, 2016. (Dissertação de mestrado).

Vellani, C. L.; Ribeiro, M. S. Sistema contábil para gestão da ecoeficiência empresarial. Revista Contabilidade e Finanças, v. 20, n. 49 , p. $25-43,2009$. https://doi.org/ 10.1590/S1519-70772009000100003

Vieira, S. A. Césio-137, um drama recontado. Estudos Avançados, v. 27, n. 77, p. 217-233, $2013 . \quad$ https://doi.org/10.1590/S010340142013000100017

Wickboldt, L. A.; Moreira, J. A. P.; Silva, M. R.; Araújo, J.S.; Silva, J. V.; Pereira, J. A. Responsabilidade ambiental ou greenwash: uma análise da evidenciação ambiental das maiores empresas brasileiras. Revista Brasileira de Gestão Ambiental e Sustentabilidade, v. 5, n. 11, p. 897-910, 2018. https://doi.org/10.21438/rbgas.

051108 